\title{
Arginine/Omega-3 Fatty Acids/Nucleotides Oral Supplement
}

National Cancer Institute

\section{Source}

National Cancer Institute. Arginine/Omega-3 Fatty Acids/Nucleotides Oral Supplement. NCI Thesaurus. Code C62534.

A specialized enteric nutritional supplement, containing substantial amounts of polyunsaturated fatty acids, arginine, and nucleotides, with potential immunostimulating activity. Compared to traditional enteric nutritional supplements, the omega-3 fatty acids/arg inine/nucleotides oral supplement may enhance the growth, development, and activity of key components of the immune system, including lymphocytes, antigen presenting cells, and various cytokines. 